\title{
COUPLING CELLULAR AUTOMATA WITH MEDALUS ASSESSMENT FOR THE DESERTIFICATION ISSUE
}

\author{
Alassane Koné $^{1 *}$, Allyx Fontaine ${ }^{2}$ and Samira El Yacoubi ${ }^{3}$ \\ ${ }^{1,2}$ UMR Espace-Dev, Université de Guyane, France \\ ${ }^{3}$ UMR Espace-Dev, IMAGES, Université de Perpignan, France \\ ${ }^{1}$ Email: alassane.kone@etu.univ-guyane.fr *(Corresponding author) \\ 2Email: allyx.fontaine@univ-guyane.fr \\ 3Email: yacoubi@univ-perp.fr
}

\begin{abstract}
Desertification is one of the major problems affecting our environment in the 21st century. Indeed, it threatens more than 1.5 million people worldwide and affects a quarter of the land in less than 100 countries, it spreads over half a billion hectares per year and reduces the surface water and groundwater. Thus, according to a report by the Food and Agriculture Organisation written in 1993, the direct and visible impacts of desertification are the damage on crops, on livestock, on the electricity productivity, etc. Indirect impacts are lack of food production, poverty, social upheaval, rural exodus to cities. In this paper, our work consists in modelling the degradation process of land whose advanced level leads to the desertification. The first step consists in assessing the degradation of land with the MEDALUS model developed by the MEDALUS project of the commission of the European Union. This model assesses desertification by its sensitivity index which is the geometric mean of four quality factor indexes of soil, vegetation, climate and management (land use). This assessment method uses the major part of the parameters influencing the land degradation process. The second step is to model the land degradation process using cellular automata (CA) approach. For that purpose, the study area will be divided into a regular grid of cells. Initially, each cell has a state (desertification sensitivity index) whose evolution at each discrete time step depends on the states of its neighbours through a built transition function. As a result, this study allows to introduce a dynamical process in MEDALUS model. Indeed, from an initial configuration of an area, the model can predict its evolution over time and space according to a continuous state transition function that extend the classical CA approach and fit to the MEDALUS model parameters.
\end{abstract}

Keywords: Cellular Automata, MEDALUS model, Desertification sensitivity index.

https://doi.org/10.47412/VQGH6804 


\section{Introduction}

Contrary to widespread opinion, desertification is not the transformation of the land into desert neither the displacement of sand dunes [17]. Indeed, according to $\mathrm{UNCCD}^{1}$, desertification is defined as the degradation of soils, landscapes and terrestrial bio-productive systems in arid, semiarid and sub-humid areas, resulting from several factors such as climate change and human activities [20]. This degradation occurs everywhere, but it is defined as desertification when it occurs in dry areas [17]. Indeed, the unsustainable use of the land resources in these areas leads to their deterioration reaching unrecoverable levels [10]. Desertification is the advanced or final step of this process [7] [9] and creates similar conditions like those of the desert [17]. Desertification has an irreversible character because if a disturbance changes the system from the vegetated state to the critical threshold of the degraded state, the removal of this disturbance will not cause the return to the initial state. Thus, the system goes from an alternately stable state to a desertified state [2] [9]. The land degradation process is also a factor of the reduction or loss of biological and economic productivity of lands, pastures and forests [17]. The areas subject to desertification are dry and characterized by low, infrequent, irregular and unpredictable rainfall; large variations between day and night temperatures; soils containing little organic matter and little water, and a fauna and a flora adapted to climatic variations (drought- resistant, adapting to salt water and able to withstand the lack of water) [16]. Desertification modelling is based on different assessment methods. A first approach is based on the prey-predator model [14] [8]. It is limited to interactions between humans and vegetation while neglecting the effects of other important factors. A second approach used to evaluate desertification relies on biological and physical variables derived from remote sensing [12]. Another approach is to quantify desertification based on indicators associated to its factors [11] [16]. These indicators come from sources of information including remote sensing images, topographic data, geological data, etc. [5] [15]. Another attempt towards building a model that would predict the risk for soil erosion, from information contained in satellite images was carried out in [4]. This paper aims at exploiting the indicator assessment made by MEDALUS ${ }^{2}$ model in order to build a cellular automaton model that will describe the spatial expansion/contraction property of the desertification phenomenon. For that purpose, CA are a good candidate as they have been successfully applied to simulate the propagation of several phenomena: fire, epidemics, pollution, etc with the ability to directly incorporate spatial heterogeneity [6][19].

This paper is organized as follows: Section 2 is devoted to some preliminaries and the proposed model is described in section 3. Some results are presented and discussed in section 4 . A conclusion is given with some perspectives at the end.

1 United Nations Convention to Combat Desertification

2 Mediterranean Desertification and Land Use 


\section{Preliminaries}

\subsection{MEDALUS model}

To model the evolution of desertification, most of the methods assess desertification from indicators. MEDALUS assessment of land degradation uses indexes of four quality factors related to the biotic and abiotic components of the environment: soil (cf. Table 4), vegetation (cf. Table 2), climate (cf. Table 3) and management (land using cf. Table 5) [1] [11] [12]. The soil parameters are composed of internal sub-factors of qualities and protection. Vegetation is the main source of soil protection against soil degradation. Human and climatic activities are the main degradation factors of soil and of its system of protection. The combined effects of these four factors give a quality state to the studied area. Each quality factor state is derived from the associated sub-factors (cf. Eq. (1)) [10]. More specifically, the index of each factor is defined by the geometric mean of its sub-factors. The desertification sensitivity index (DSI) is determined by the geometric mean of the quality index of the factors soil $\left(s^{\mathrm{l}}\right)$, vegetation $\left(\mathrm{s}^{\mathrm{v}}\right)$, climate $\left(\mathrm{s}^{\mathrm{cl}}\right)$ and management $\left(\mathrm{s}^{\mathrm{m}}\right)$ [9] which are in the range [1;2]. Its range values and its associated state quality are defined in Table 1.

$$
\text { DSI }=\left(s^{1} * s^{\mathrm{v}} * \mathrm{~s}^{\mathrm{cl}} * \mathrm{~s}^{\mathrm{m}}\right)^{\frac{1}{4}}
$$

Table 1: States of desertification sensitivity index DSI in MEDALUS according to [5] [8]

\begin{tabular}{|c|c|c|c|c|c|}
\hline Class of state & $\mathrm{I}_{5}=[1.78 ; 2[$ & $\mathrm{I}_{4}=[1.53 ; 1.78[$ & $\mathrm{I}_{3}=[1.38 ; 1.53[$ & $\mathrm{I}_{2}=[1.22 ; 1.38[$ & $\mathrm{I}_{1}=[1 ; 1.22[$ \\
\hline State of DSI & $\begin{array}{c}\text { Very- } \\
\text { degraded }\end{array}$ & Degraded & High & Moderate & Low \\
\hline
\end{tabular}

Table 2: Sub-factors indexes of vegetation factor in MEDALUS model according to [1]

\begin{tabular}{|c|c|c|c|c|}
\hline Sub-factor & Class & Description & Characterization & Index \\
\hline \multirow{3}{*}{ Fire risk } & 1 & Low & Earth, Chott and Sebkha & 1.0 \\
\hline & 2 & Moderate & Courses, hills & 1.3 \\
\hline & 3 & Very high & Cultures, forests & 2.0 \\
\hline \multirow{4}{*}{$\begin{array}{c}\text { Erosion } \\
\text { protection }\end{array}$} & 1 & Very high & Cultures, forests & 1.0 \\
\hline & 2 & High & Mountainous areas & 1.3 \\
\hline & 3 & Moderate & Courses, hills & 1.8 \\
\hline & 4 & Low & Arab’s earth and Chott Sebkha & 2 \\
\hline \multirow{4}{*}{$\begin{array}{l}\text { Drought } \\
\text { resistance }\end{array}$} & 1 & High & Mountainous areas & 1.2 \\
\hline & 2 & Moderate & Earth, Chott and Sebkha & 1.4 \\
\hline & 3 & Low & Courses, hills & 1.7 \\
\hline & 4 & Very low & Cultures, forests & 2.0 \\
\hline \multirow{3}{*}{ Vegetation cover } & 1 & High & $>40 \%$ & 1.0 \\
\hline & 2 & Low & $10-40 \%$ & 1.8 \\
\hline & 3 & Very low & $<10 \%$ & 2 \\
\hline
\end{tabular}


Table 3: Sub-factors indexes of climate factor in MEDALUS model according to [1]

\begin{tabular}{|c|c|c|c|c|}
\hline Sub-factor & Class & Description & Characterization & Index \\
\hline \multirow{3}{*}{ Rainfall } & 1 & High & $>500 \mathrm{~mm}$ & 1.0 \\
\hline & 2 & Moderate & $250-500 \mathrm{~mm}$ & 1.5 \\
\hline & 3 & Low & $<250 \mathrm{~mm}$ & 2.0 \\
\hline \multirow{6}{*}{ Aridity } & 1 & Humid & $\mathrm{P} / \mathrm{P} \mathrm{E} \geq 0.75$ & 1.0 \\
\hline & 2 & wet sub-humid & $0.65-0.75$ & 1.1 \\
\hline & 3 & dry sub-humid & $0.5-0.65$ & 1.2 \\
\hline & 4 & Semi-arid & $0.2-0.5$ & 1.4 \\
\hline & 5 & Arid & $0.05-0.2$ & 1.8 \\
\hline & 6 & Hyper-arid & $\mathrm{P} / \mathrm{P} \mathrm{E}<0.05$ & 2 \\
\hline \multirow{2}{*}{ Slope orientation } & 1 & Good & North-west, North-east & 1.0 \\
\hline & 2 & Low & South-west, South-east & 2.0 \\
\hline
\end{tabular}

Table 4: Sub-factors indexes of soil factor in MEDALUS model according to [10] [13]

\begin{tabular}{|c|c|c|c|c|}
\hline Sub-factor & Class & Description & Characterization & Index \\
\hline \multirow{4}{*}{ Texture } & 1 & Good & mean and sandy & 1.0 \\
\hline & 2 & Moderate & Sandy clay, silty and medium & 1.2 \\
\hline & 3 & Poor & Clay, clayey silt & 1.6 \\
\hline & 4 & Very poor & Very sandy & 2.0 \\
\hline \multirow{3}{*}{ Parent material } & 1 & Good & $\begin{array}{l}\text { Shale, basic and ultrabasic rock, } \\
\text { conglomerate, unconsolidated rocks }\end{array}$ & 1.0 \\
\hline & 2 & Moderate & $\begin{array}{l}\text { Limestone, marble, granite, riolite, } \\
\text { ignimbrite, gneiss, sandstone, siltite }\end{array}$ & 1.7 \\
\hline & 3 & Poor & Marne, pyroclastic rocks & 22 \\
\hline \multirow{4}{*}{ Slope } & 1 & $\begin{array}{l}\text { Flat, wavy } \\
\text { undulated }\end{array}$ & $<6 \%$ & 1.0 \\
\hline & 2 & Corrugated & $6-18 \%$ & 1.2 \\
\hline & 3 & Inclined & $18-35 \%$ & 1.5 \\
\hline & 4 & Very inclined & $>35 \%$ & 2.0 \\
\hline \multirow{3}{*}{ Stoniness } & 1 & Very stony & $>60 \%$ & 1.0 \\
\hline & 2 & Stony & $20-60 \%$ & 1.3 \\
\hline & 3 & Low stony & $<20 \%$ & 2 \\
\hline \multirow{3}{*}{ Drainage } & 1 & Good & Good system of drainage & 1.0 \\
\hline & 2 & Moderate & Imperfect drainage system & 1.2 \\
\hline & 3 & Low & Bad drainage system & 2.0 \\
\hline \multirow{4}{*}{ Depth } & 1 & Deep & $>75 \mathrm{~cm}$ & 1.0 \\
\hline & 2 & Moderate & $30-75 \mathrm{~cm}$ & 1.4 \\
\hline & 3 & Low & $15-30 \mathrm{~cm}$ & 1.7 \\
\hline & 4 & Very low & $<15 \mathrm{~cm}$ & 2.0 \\
\hline
\end{tabular}


Table 2 : Sub-factors indexes of management factor in MEDALUS model according to [1] [13]

\begin{tabular}{|c|c|c|c|c|}
\hline Sub-factor & Class & Description & Characterization & Index \\
\hline \multirow{3}{*}{ Crops } & 1 & Low using intensity of soil & & 1.0 \\
\hline & 2 & Mean using intensity of soil & & 1.5 \\
\hline & 3 & High using intensity of soil & & 2.0 \\
\hline \multirow{4}{*}{ Pasture } & 1 & Low density & $<20$ head by km² & 1.0 \\
\hline & 2 & Moderate density & 20-60 head by km² & 1.33 \\
\hline & 3 & High density & 60-100 head by km² & 1.66 \\
\hline & 4 & Very high density & $>100$ head by km² & 2.0 \\
\hline \multirow{5}{*}{$\begin{array}{l}\text { Population } \\
\text { growth }\end{array}$} & 1 & Very low & $<0 \%$ & 1.0 \\
\hline & 2 & Low & $0-1.5 \%$ & 1.2 \\
\hline & 3 & Moderate & $1.5-3 \%$ & 1.4 \\
\hline & 4 & High & $3-6 \%$ & 1.8 \\
\hline & 5 & Very high & $>6 \%$ & 2.0 \\
\hline
\end{tabular}

The desertification sensitivity indexes provided by MEDALUS will serve to build a spatiotemporal model based on CA approach.

\subsection{Cellular Automata (CA) Approach}

A cellular automaton is defined by a tuple ( $\mathrm{L} ; \mathrm{S} ; \mathrm{V} ; \mathrm{f})$ [3] where $\mathrm{L}$ is a two-dimensional network of cells defined by: $\mathrm{L}=\{0 ; 1 ; . . ; \mathrm{W}\} \times\{0 ; 1 ; \ldots ; \mathrm{H}-1\}$. Geometrically, $\mathrm{L}$ may be a rectangle with width $\mathrm{W}$ and height $\mathrm{H}$ and it is composed of W. $\mathrm{H}$ cells; $\mathrm{S}$ is a finite set of cells states and represents all the states that can be taken by each cell; $\mathrm{V}$ is the neighbourhood set that contains all the cells whose states have an impact on the evolution of a central cell c. If each cell has $\mathrm{n}$ neighbours, the neighbourhood of a cell $\mathrm{c}$ is denoted by $\left(\mathrm{c}_{1} ; \mathrm{c}_{2} ; \ldots, \mathrm{c}_{\mathrm{n}}\right)$. The three most used neighbourhood types are presented in Fig. 1.

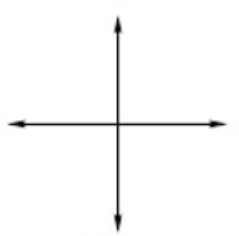

von Neumann

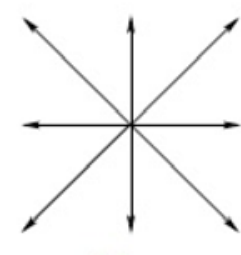

Moore

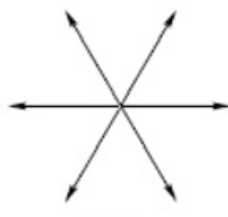

Uniform

Figure 1

The transition function $\mathrm{f}$ calculates the state of a cell at time $\mathrm{t}+1$ using its neighbourhood state at time t. One step of the time represents one year in our model. Let $s_{c}(t)$ be the state of a cell $c$ at time $t$ and $\left(\mathrm{s}_{\mathrm{c}_{1}}(\mathrm{t}) ; \mathrm{s}_{\mathrm{c}_{2}}(\mathrm{t}) ; \ldots ; \mathrm{s}_{\mathrm{c}_{\mathrm{n}}}(\mathrm{t})\right)$ its neighbourhood state at time $\mathrm{t}$. The transition function can be defined by:

$$
f: S^{n} \rightarrow S
$$




$$
\left(\mathrm{s}_{\mathrm{c}_{1}}(\mathrm{t}) ; \mathrm{s}_{\mathrm{c}_{2}}(\mathrm{t}) ; \ldots ; \mathrm{s}_{\mathrm{c}_{\mathrm{n}}}(\mathrm{t})\right) \mapsto \mathrm{s}_{\mathrm{c}}(\mathrm{t}+1)
$$

The global function $\mathrm{F}$ associates to the cellular automaton configuration at time $\mathrm{t}$, a new configuration at time $t+1$. If $S^{\mathrm{L}}$ is the set of all the cellular automaton configuration defined on the grid $\mathrm{L}, \mathrm{s}(\mathrm{t})$ and $\mathrm{s}(\mathrm{t}+1)$ two consecutive configurations.

$\mathrm{F}$ is defined by Eq. (3).

$$
\begin{gathered}
F: S^{L} \rightarrow S^{L} \\
\mathbf{s}(\mathbf{t}) \mapsto \mathbf{F}(\mathbf{s}(\mathbf{t}))=\mathbf{s}(\mathbf{t}+\mathbf{1})
\end{gathered}
$$

\section{Proposed Model}

The methodology adopted in this paper consists in representing the evolution of the desertification phenomenon by means of a cellular automaton model ( $\mathrm{L} ; \mathrm{S} ; \mathrm{V} ; \mathrm{f}$ ) whose transition function $\mathrm{f}$ is based on the MEDALUS assessment.

\subsection{Cellular Space}

A cellular automaton is defined on a regular grid where each element called cell has a position and a shape depending on the space dimension and on the considered phenomenon. We denoted by $c_{i j}$ the cell in a 2D space $\mathrm{L}$ whose coordinates are $(i ; j)$. The evolution of this grid is based on the desertification sensitivity index of each cell that will serve to establish the transition rules according to the chosen neighbourhood.

\subsection{Cell State}

Each cell has a state chosen in a finite set that can evolve over time. However, the land evolution is obtained by the intensity of degradation factors and the implicit interactions between them. This evolution implies a speed of degradation. By fixing states in a discrete set, the speed of degradation is implicitly suppressed. To correct this fact in our work, an extended version of the classical CA named continuous CA that uses continuous state, will be used. The state of a cell will be described in a range value [1;2]. The cell state expresses its degradation state which is also its participation level to the desertification process. In fact, a cell having a low or moderate state participates weakly in the degradation process and a cell with a degraded or very degraded state participates actively in a spreading of desertification phenomenon. The cells states are in the interval [1;2]. We denote by $\mathrm{s}_{\mathrm{c}}(\mathrm{t})$ the state of a cell $\mathrm{c}$ at the time t.When the cell and time are clearly indicated, we will simplify the notation of the state $s_{c}(t)$ by s and the state of the cell $c$ at the next time will be denoted s+.

\subsection{Neighbourhood}

The neighbourhood is chosen by the fact that the evolution of an area is primarily based on its interactions with all surrounding areas. The human activities and climatic parameters of each cell affect its neighbourhood land. Thus, the Moore's neighbourhood order 1 is suitable to model the interaction between the different parameters of lands and it corresponds to a radius $r=1$. Let $\mathcal{N}_{c}$ be the neighbourhood of a cell $\mathrm{c}=c_{i j}$ of size $\left|\mathcal{N}_{\mathrm{c}}\right|=8$ such that: 


$$
\mathcal{N}_{\mathrm{c}}=\left\{c_{i^{\prime} j^{\prime}} \in \mathrm{L}, \max \left(\left|\mathrm{i}-\mathrm{i}^{\prime}\right|,\left|\mathrm{j}-\mathrm{j}^{\prime}\right|\right)<\mathrm{r}\right\}
$$

\subsection{Transition Function}

The transition function considers the state of each cell and its interactions with its neighbourhood. These interactions allow to define the stress conditions for a given cell. Indeed, a cell is in the stress condition if its state and its neighbourhood state reach extreme conditions or huge degradation levels such as high, degraded and very degraded state. Let $\mathcal{N}_{\mathrm{c}}=\left(\mathrm{c}_{1}, \mathrm{c}_{2}, \ldots, \mathrm{c}_{8}\right)$ be the neighbourhood of cell $\mathrm{c}$ where $\mathrm{c}_{i}$ and $\mathrm{s}_{\mathrm{c}_{i}}$ represent respectively the i-th neighbour of the cell $\mathrm{c}$ and its state at time t. The global state $\mathrm{s}_{\mathcal{N}_{\mathrm{c}}}$ of the neighbourhood $\mathcal{N}_{\mathrm{c}}$ is given by:

$$
\mathrm{s}_{\mathcal{N}_{\mathrm{c}}}=\left(\mathrm{s}_{\mathrm{c}_{1}} \times \mathrm{s}_{\mathrm{c}_{2}} \times \ldots \times \mathrm{s}_{\mathrm{c}_{8}}\right)^{\frac{1}{8}}
$$

The stress cells verify Eq. (6) and Eq. (7).

Case 1: The states of cell $\mathrm{c}$ and its neighbourhood reach the upper part of the range of degraded state such as:

$$
\frac{\min \left(\mathrm{I}_{4}\right)+\min \left(I_{5}\right)}{2} \leq \mathrm{S}_{c}<\min \left(\mathrm{I}_{5}\right) \text { and } \frac{\min \left(\mathrm{I}_{4}\right)+\min \left(I_{5}\right)}{2} \leq \mathrm{s}_{\mathcal{N}_{c}}<\min \left(\mathrm{I}_{5}\right)
$$

Case 2: The state of cell c reaches the upper part of the range of high state and its neighbourhood reaches the upper part of the range of very degraded state:

$$
\frac{\min \left(\mathrm{I}_{3}\right)+\min \left(\mathrm{I}_{4}\right)}{2} \leq \mathrm{S}_{\mathrm{c}}<\min \left(\mathrm{I}_{4}\right) \text { and } \frac{\min \left(\mathrm{I}_{5}\right)+\max \left(\mathrm{I}_{5}\right)}{2} \leq \mathrm{s}_{\mathcal{N}_{\mathrm{C}}}
$$

where $\mathrm{I}_{3}, \mathrm{I}_{4}$ and $\mathrm{I}_{5}$ are described in Table 1 .

Let $f$ be the transition function, defined in Eq. (8) and Eq. (9), that maps the state $\mathrm{s}_{\mathrm{c}}$ of cell $\mathrm{c}$ at time $t$ to its state $s_{c}^{+}$at time $t+1$ according to its neighbourhood state $s_{\mathcal{N}_{c}} \cdot s_{c}^{+}$is given by the geometric mean of its index $s_{\mathrm{c}}$ and the index of its neighbourhood $s_{\mathcal{N}_{\mathrm{c}}}$ at time t. However, if the cell $\mathrm{c}$ is in a very degraded state and its neighbourhood is in high or degraded state, it keeps its state at time $t+1$ and a stress cell changes its state to a superior state. These fundamental rules are explained by these facts: (1) Desertified or very degraded state is almost irreversible in degradation situation [2] [9] and (2) bad climate conditions and human pressures lead to a stress in the exposed land by the degradation process [18].

$$
\begin{aligned}
& \mathrm{f:}[1 ; 2] \times[1 ; 2] \rightarrow[1 ; 2] \\
& \left(\mathrm{s}_{\mathrm{c}}, \mathrm{s}_{\mathcal{N}_{\mathrm{c}}}\right) \mapsto \mathrm{s}_{\mathrm{c}}^{+}
\end{aligned}
$$




$$
\mathrm{s}_{\mathrm{c}}^{+}=\left\{\begin{array}{l}
\operatorname{Id}\left(\mathrm{s}_{\mathrm{c}}\right) \text { if } \mathrm{s}_{\mathrm{c}} \in \mathrm{I}_{5} \text { and }\left(\mathrm{s}_{\mathcal{N}_{\mathrm{c}}} \in \mathrm{I}_{3} \text { or } \mathrm{s}_{\mathcal{N}_{\mathrm{c}}} \in \mathrm{I}_{4}\right) \\
\mathrm{s}_{\mathcal{N}_{\mathrm{c}}} \text { if } \mathrm{s}_{\mathrm{c}} \in \mathrm{I}_{4} \text { and } \mathrm{s}_{\mathcal{N}_{\mathrm{c}}} \in \mathrm{I}_{5} \\
\min \left(\mathrm{I}_{5}\right) \text { if } \mathrm{s}_{\mathrm{c}} \text { and } \mathrm{s}_{\mathcal{N}_{\mathrm{c}}} \text { verifie Eq. (6) } \\
\min \left(\mathrm{I}_{5}\right) \text { if } \mathrm{s}_{\mathrm{c}} \text { and } \mathrm{s}_{\mathcal{N}_{\mathrm{c}}} \text { verifie Eq. (7) } \\
\left(\mathrm{s}_{\mathrm{c}} \times \mathrm{s}_{\mathcal{N}_{\mathrm{c}}}\right)^{\frac{1}{2}} \text { if not }
\end{array}\right.
$$

where Id is identity function, $\mathrm{I}_{3}$ is range of high state, $\mathrm{I}_{4}$ range of degraded state and $\mathrm{I}_{5}$ range of very degraded state in Table 1.

$$
\mathrm{s}_{\mathrm{c}}^{+} \text {is qualified as }\left\{\begin{array}{l}
\text { low if } \mathrm{s}_{\mathrm{c}}^{+} \in \mathrm{I}_{1} \\
\text { moderate if } \mathrm{s}_{\mathrm{c}}^{+} \in \mathrm{I}_{2} \\
\text { high if } \mathrm{s}_{\mathrm{c}}^{+} \in \mathrm{I}_{3} \\
\text { degraded if } \mathrm{s}_{\mathrm{c}}^{+} \in \mathrm{I}_{4} \\
\text { very degraded if } \mathrm{s}_{\mathrm{c}}^{+} \in \mathrm{I}_{5}
\end{array}\right.
$$

Thus, depending on a cell state and its neighbourhood, three kinds of processes can be described: degradation, regeneration and stability. A cell $\mathrm{c}$ is in the process of degradation if its state $\mathrm{s}_{\mathrm{c}}$ is in a range inferior to the range of its neighbourhood state $s_{\mathcal{N}_{c}}$ in Table 1 excepted the case of Eq. (7). i.e. $s_{c}<s_{c}^{+}$. A cell $c$ is in the process of regeneration if its state $s_{c}$ is in a range superior to the range of its neighbourhood state $s_{\mathcal{N}_{c}}$ in Table 1. i.e. $s_{c}>s_{c}^{+}$. A cell $c$ is in the process of stability or conservation if its state $s_{c}$ is in the same range with its neighbourhood state $s_{\mathcal{N}_{c}}$ excepted the case of Eq. (6). A degraded cell is in the stress state when its neighbourhood states reaches a certain value of the degraded level (Eq. (6) and Eq. (7)). The states of all stress cells change from high or degraded to degraded or very degraded. The transition rules are obtained by applying the transition function defined by Eq. (9). For example, if a cell c and its neighbourhood $\mathcal{N}_{\mathrm{c}}$ is in the low state at time $\mathrm{t}$, it will keep its state at time $\mathrm{t}+1$. If the cell $\mathrm{c}$ is in the low state and its neighbourhood $\mathcal{N}_{\mathrm{c}}$ is in a high state at time $\mathrm{t}$, it becomes degraded and its state at time $\mathrm{t}+1$ will be moderated. If a cell $\mathrm{c}$ is in a high state and its neighbourhood $\mathcal{N}_{\mathrm{c}}$ is in a low state at time t, it will be regenerated and its state at time $\mathrm{t}+1$ will be moderate.

\section{Results and Discussion}

\subsection{Initial State/Configuration}

The initial configuration of the studied area is given by the quality index of the four desertification factors. The initial state of each cell $\mathrm{c}$ is given by its desertification sensitivity index $\mathrm{s}_{\mathrm{c}}$. Each value of $\mathrm{s}_{\mathrm{c}}$ according to Table 1, corresponds to a quality state which can be low, moderate, high, degraded and very degraded. Let $s_{c}^{l}(0), s_{c}^{v}(0), s_{c}^{c l}(0)$ and $s_{c}^{m}(0)$ be soil, vegetation, climate and the management quality indexes of a cell $\mathrm{c}$ at initial time $\mathrm{t}=0$. The initial desertification sensitivity index $s_{c}(0)$ of each cell $c$ is given by:

$$
s_{c}(0)=\left(s_{c}^{l}(0) \times s_{c}^{v}(0) \times s_{c}^{c l}(0) \times s_{c}^{m}(0)\right)^{\frac{1}{4}}
$$

And denote by $s(0)=\left\{s_{c}(0) ; c \in L\right\}$ the initial configuration of the cellular automata. 
We used for our simulations in this work simulated data from MEDALUS model that compose four matrices $\mathrm{s}^{\mathrm{l}}, \mathrm{s}^{\mathrm{v}}, \mathrm{s}^{\mathrm{cl}}$ and $\mathrm{s}^{\mathrm{m}}$ of dimension $\mathrm{W} \times \mathrm{H}$ where $\mathrm{W}$ and $\mathrm{H}$ are the lattice's width and height respectively. In our example $\mathrm{W}=\mathrm{H}=40$. The initial data are put in the matrices $\mathrm{s}^{\mathrm{l}}, \mathrm{s}^{\mathrm{v}}, \mathrm{s}^{\mathrm{cl}}$ and $\mathrm{s}^{\mathrm{m}}$ whose values are between 1 and 2 . These matrices correspond respectively to the initial indexes of soil, vegetation, climate and management factors. The data from these matrices are used to determine the initial state s of the grid which is presented in Fig. 2a.

\subsection{Results and Discussion}

The built CA model was implemented using a Python code and the evolution of the studied area starting from the described initial state is represented in Fig. 2. The elementary processes of degradation, regeneration and stability are observed. The very degraded cells (in orange) actively participate in the degradation of cells states. Thus, the neighbouring area in a good quality state (in dark green) is degraded by them progressively until reaching advanced degradation levels. This is explained by the fact that in advanced degradation conditions, climatic parameters are bad and human activities are intense. This situation creates additional pressures on neighbouring lands until their progressive degradation. Before the degradation, the good state cells (low and moderate) improve their neighbourhood with moderate state because their good climatic conditions and good human practices positively influence practices in non desertified areas. In the degraded zone (in yellow), the stress cells are desertified from time $t=10$ and subsequently contributed to the desertification of the degraded area. The curves on Fig. 3 shows that the elementary processes of degradation, regeneration and stability take place. Initially, very degraded cells curve is growing and degraded cells curve is decreasing. Indeed, the major part of degraded cells became very degraded (desertified). The non-symmetrical form of the two curves is explained by the fact that certain cells according to their state do not transit by the degraded state before being desertified. Indeed, if a cell has a high state and its neighbourhood has an upper part of desertification level, this cell goes directly to the desertified state. The evolution of the number of cells with low degradation is decreasing because the bad neighbouring climatic conditions and the human activities expansion deteriorate their states. The moderate state curve trend is increasing and decreasing. Its increase is essentially done by the cell with low state deterioration. It decreases when cell with low state are stabilized and thereafter the moderate state cells are deteriorated to high or degraded cell state. The trend of high cell state is almost stable because it represents the degradation transit state between moderate and degraded states. The major part of cells goes through high state before degrading. 


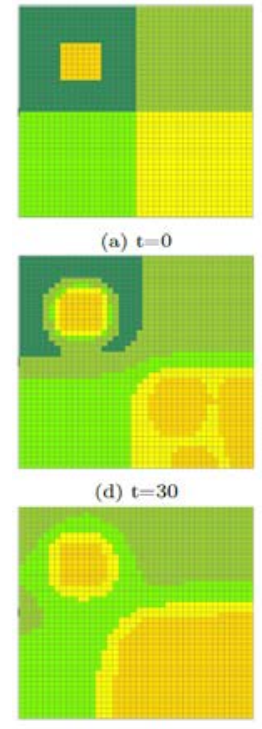

(g) $\mathrm{t}=175$

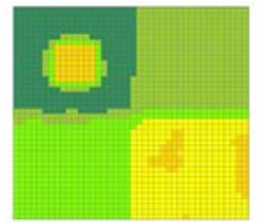

(b) $t=10$

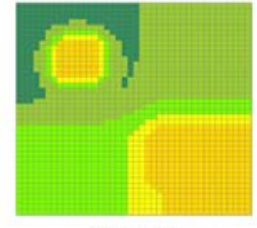

(e) $\mathrm{t}=40$

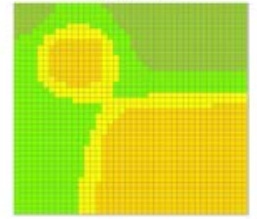

(h) $\mathrm{t}=215$

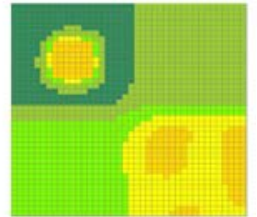

(c) $t=20$

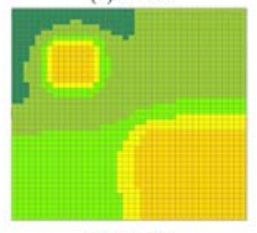

(f) $\mathrm{t}=60$

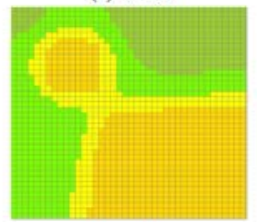

(i) $\mathrm{t}=\mathbf{2 3 0}$

Figure 2: Evolution of an area initially distributed by the sensitivity level to the desertification

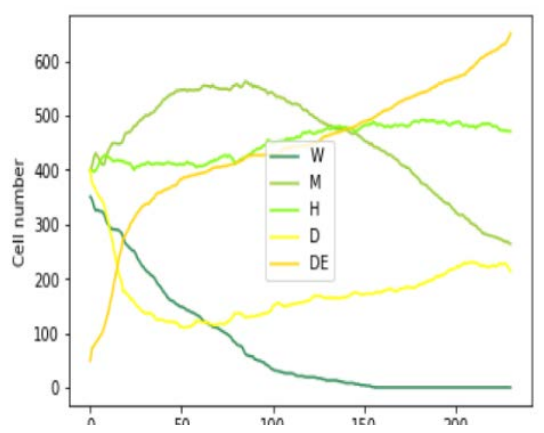

Figure 3: Evolution of the number of cells in various sensitivity levels to the desertification during the time interval $[0 ; 230]$ in the considered study area

$\mathrm{W}=$ Low, $\mathrm{M}=$ Moderate, $\mathrm{H}=$ High, $\mathrm{D}=$ Degraded and $\mathrm{DE}=$ Very degraded.

\section{Conclusion}

The piece of work presented in this paper constitutes a first attempt towards constructing a more realistic model that would assess the desertification expansion in risked areas. The proposed model was based on a continuous cellular automaton whose state set and transition function were extracted from the MEDALUS method. This model allowed to predict the evolution of an area with moderate slope and an annual time step. The considered cell evolution is strongly influenced by practices around. The used of Moore neighbourhood of radius 1 allows to consider the influence of all the surrounding neighbouring cells. The elementary processes of degradation, regeneration and stability are well observed. The realized curves trends show these processes and the interaction between the different states in evolution process of land. In this MEDALUS based model, parameters are used to calculate the cells initial states.

The combination of MEDALUS method and CA approach introduced a dynamical process in the model. Indeed, this coupling operation allows to predict the evolution of the studied area in time and space. Moreover, the different ranges of values in MEDALUS model are fixed. This fact could cause a discontinuity between the data because its evolution can generate non homogeneous classes. As a perspective, the ranges of values can be determined by a classification method to ensure homogeneity in data evolution and each MEDALUS parameter can be evolved through established rules based on their basic processes. Moreover, to avoid the trend in a complete degradation of all cells, some control parameters will be introduced in the next step of our work. These parameters will help to follow the spreading of the desertification phenomenon and to act with management action. Also, a study of the relative fronts between degraded and non-degraded areas is worth considering.

Finally, it should be stressed that the simulation was performed on an artificial study area with a structured heterogeneity. A randomly distributed initial state is currently under consideration and 
the future work will be devoted to a real situation in Saharan Niger where the desertification phenomenon constitutes a major problem.

\section{References}

[1] F. Boudjemline and A. Semar. Assessment and mapping of Desertification Sensitivity with MEDALUS model and GIS - case study: Basin of Hodna, Algeria. Journal of Water and Land Development, 36:17-26, 032018.

[2] P. Dódorico, A. Bhattachan, F. Davis, K., S. Ravi, and W. Runyan, C. Global desertification: Drivers and feedbacks. Advances in Water Resources, 51:326-344, January 2013.

[3] S. El Yacoubi and A. El Jai. Cellular automata modelling and spreadability. Mathematical and Computer Modelling, 36(9):1059 - 1074, 2002.

[4] S. El Yacoubi, M. Fargette, A. Faye, W. de Carvalho Junior, T. Libourel, M. Loireau: A multilayer perceptron model for the correlation between satellite data and soil vulnerability in the Ferlo, Senegal. International Journal of Parallel Emergent and Ditributed Systems IJPEDS 34(1): 3-12 (2019)

[5] A. Gad and I. Lotfy. Use of remote sensing and GIS in mapping the Environmental Sensitivity Areas for desertification of egyptian territory. eEarth Discussions, 3, 062008.

[6] J. Gouveia Freire and C. Castro DaCamara, Using cellular automata to simulate wildfire propagation

and to assist in fire management, Nat. Hazards Earth Syst. Sci., 19: 169-179, 2019.

[7] J. Hill. Land and soil degradation assessments in Mediterranean Europe. GMES-LADAMER. 2003.

[8] J. Ibáñez, M. Valderrama, and J. Puigdefábregas. Assessing desertification risk using system stability condition analysis. Ecological Modelling, pages 180-190, 2008.

[9] C. Kosmas, M. Tsara, N. Moustakas, and C. Karavitis. Identification of indicators for desertification. Annals of Arid Zone, 42:393-416, 092003.

[10] C. Kosmas, A. Ferrara, H. Briassouli, and A. Imeson. Methodology for mapping Environmentally Sensitive Areas (ESAs) to desertification, 31-47 pages, 01-1999.

[11] H. Lahlaoi, H. Rhinane, A. Hilali, S. Lahssini, and S. Moukrim. Desertification assessment using MEDALUS model in watershed Oued El Maleh, Morocco. Geosciences, 7:2-16, 072017.

[12] S. Liang. Narrowband to broadband conversions of land surface albedo i: Algorithms. Remote Sensing of Environment, 76(2):213 - 238, 2001.

[13] L. Montanarella, R. Paracchini, and E. Rusco. Programme d'action pour la lutte contre la secheresse et la desertification: Indications des zones vulnerables dans la région de Puglia. 42:34 pages, 2000.

[14] J. Puigdefábregas. Desertification: Stress beyond resilience, exploring a unifying process structure. 1995.

[15] H. Ranjbaran, H. Shurvarzy, and A. Alimohammadi. Mapping desertification using Iranian Model of Desertification Potential Assessment (IMDPA) and GIS in Golestan Province, Iran. Bulletin of Environment, Pharmacology and life sciences, pages 117-128, 2014.

[16] M. Rasmy, A. Gad, H. Abdelsalam, and M. Siwailam. A dynamic simulation model of desertification in Egypt. The Egyptian Journal of Remote Sensing and Space Sciences, 13(2):101111, 2010.

[17] Secrétariat de la Convention des Nations Unies sur la Lutte contre la Désertification (CNULD). Désertification: Une synthèse visuelle. Centre International UNISFERA, Jul 2011. 
[18] P. Shoba and S. S. Ramakrishnan. Modeling the contributing factors of desertification and evaluating their relationships to the soil degradation process through geomatic techniques. Solid Earth, 7:341-354, mars 2013.

[19] R. Slimi, S. El Yacoubi, Spreadable cellular automata: modelling and simulations. Int. J. Systems Science 40(5): 507-520 (2009)

[20] P. Tchakerian, V. Desertification: Exploding the myth by David S. G. Thomas and Nicholas J. Middleton, Wiley, Hichester. Earth Surface Processes and Landforms, 21(8):780-780, 1994. 